\title{
Colchicine protects mice from the lethal effect of an agonistic anti-Fas antibody
}

\author{
Guoping Feng and Neil Kaplowitz \\ Research Center for Liver Diseases, Keck School of Medicine, University of Southern California, \\ Los Angeles, California 90033, USA \\ Address correspondence to: Neil Kaplowitz, Keck School of Medicine, 2011 Zonal Avenue, \\ HMR 101, Los Angeles, California 90033, USA. \\ Phone: (323) 442-5576; Fax: (323) 442-5425; E-mail: kaplowit@hsc.usc.edu. \\ Received for publication May 21, 1999, and accepted in revised form December 14, 1999.
}

The aim of this study was to determine whether colchicine, which has been reported to protect against various hepatotoxic insults, influences the susceptibility of mice to the agonistic anti-Fas antibody, Jo2. All mice that were pretreated with colchicine $(2 \mathrm{mg} / \mathrm{kg})$ survived the lethal challenge of intraperitoneal administration of $10 \mu \mathrm{g}$ of Jo2, whereas all control mice pretreated with $\gamma$-lumicolchicine succumbed to the challenge. Twelve micrograms of Jo2 killed less than half of colchicinepretreated mice and its lethal effects were delayed relative to control mice, which all died within 8 hours. Other microtubule-disrupting agents such as Taxol, vinblastine, and nocodazole also improved the survival of mice treated with the lethal dose of Jo2. Histologic examination showed that colchicine protected against Jo2-induced fulminant liver injury, and TUNEL assay demonstrated that colchicine protected against massive apoptosis of hepatocytes. Hepatocytes isolated from colchicine-pretreated mice exhibited decreased susceptibility to Jo2-induced apoptosis. In addition, colchicine pretreatment reduced surface expression of Fas and decreased Jo2- and TNF$\alpha$-induced apoptosis of cultured hepatocytes in the presence of actinomycin D, but did not affect the susceptibility of cultured sinusoidal endothelial cells to Jo2-induced apoptosis. Remarkably, Fas and TNF receptor-1 mRNA and intracellular protein levels increased after colchicine treatment, indicating that colchicine protects against death ligand-induced apoptosis in the liver by decreasing death-receptor targeting to the cell surface.

J. Clin. Invest. 105:329-339 (2000).

\section{Introduction}

Apoptosis is induced in response to various pathologic and physiologic stimuli, such as activation of cell-surface death receptors, UV radiation, serum withdrawal, and cytotoxic drugs $(1,2)$. Apoptosis plays an important role in animal development (3), maintenance of tissue homeostasis $(2,3)$, regulation of the immune system (4), and the host response to insult $(2,5)$. It is morphologically characterized by cell shrinkage, chromatin condensation, membrane blebbing, and formation of apoptotic bodies (5). Caspases (aspartate-specific cysteine proteases) are an essential part of the apoptosis machinery. Most proteases are synthesized as inactive precursors. The precursors are usually converted to the active enzymes after they are cleaved by another protease or by autocatalysis $(6,7)$. Fas (also known as CD95/APO-1) is widely expressed in various tissues such as liver, thymus, heart, and kidney $(8,9)$. Fas belongs to the TNF receptor (TNFR) superfamily, which includes TNFR-1, TNFR-2, DR3, DR4, DR5, and P75 nerve growth factor receptor $(10,11)$. Fas ligand is primarily expressed in cytotoxic lymphocytes and immune privilege sites (12, 13). The Fas-mediated death pathway is activated by binding Fas ligand or agonistic anti-Fas antibody to Fas, triggering trimerization and intracellular signaling. Liver is extremely sensitive to Fas-mediated apoptosis.
Intraperitoneal administration of agonistic anti-Fas antibody (Jo2) rapidly kills mice by causing fulminant liver injury with diffuse hemorrhage and massive apoptosis of hepatocytes (14). Fas-mediated apoptosis is involved in a variety of liver diseases $(15,16)$, in the host response to some hepatotoxic insults, and in liver homeostasis. Hepatic Fas expression is elevated in chronic hepatitis B (17), chronic hepatitis C (18), and acute liver failure (19). Fas ligand plays an important role in the development of hepatitis (20). Increased hepatic Fas ligand expression has been found in hepatocytes from patients with alcoholic liver injury (19) and Wilson's disease (21). Targeted mutations in the Fas gene lead to hyperplasia of the liver (22). Metastatic cancers may take advantage of high expression of Fas in hepatocytes, expressing Fas ligand to invade and colonize the liver through induction of apoptosis of surrounding hepatocytes (23).

Colchicine is an antimitotic agent and an effective treatment for acute gouty arthritis. Colchicine interferes with the function of microtubules by binding to microtubular protein (tubulin) and causing depolymerization of microtubules (24). Microtubules are involved in diverse functions, including cell movement, vesicle transport, and chromosome segregation during mitosis. It has been shown that colchicine can 
be either cytotoxic or protective against cytotoxicity. Colchicine has been reported to protect against a variety of hepatotoxic insults, such as acetaminophen (25), $\mathrm{CCl}_{4}(26)$, and TNF/LPS toxicity in galactosamine-sensitized animals (27). Colchicine was reported to improve survival in a clinical trial for alcoholic liver cirrhosis (28), and is currently under investigation in a long-term Veterans Administration cooperative treatment trial in alcoholic liver disease. In this report, we address whether colchicine changes the susceptibility of mice to the lethal effect of agonistic anti-Fas antibody, and the possible mechanism. Our results show that colchicine protects mice against fulminant liver injury induced by anti-Fas antibody. It is likely that this protection is due to the downregulation of Fas density on the hepatocyte surface.

\section{Methods}

Mice and reagents. Male C57BL/6 mice were obtained from Harlan Bioproducts for Science Inc. (Indianapolis, Indiana, USA). Male p53-knockout C57BL/6 mice were from Taconic (Germantown, New York, USA). All the mice were used at the age of 6-7 weeks. Anti-Fas antibody (Jo2) was obtained from PharMingen (San Diego, California, USA), and was administered to mice intraperitoneally in $200 \mu \mathrm{L}$ of PBS. Colchicine, $\gamma$-lumicolchicine, vinblastine, paclitaxel (Taxol), cytochalasin $\mathrm{B}$, nocodazole, and staurosporine were purchased from Sigma Chemical Co. (St. Louis, Missouri, USA), and were dissolved in dimethyl sulfoxide as stock solutions. All other chemicals were purchased from reputable commercial sources.

Histology. Mice were sacrificed 4 hours after injection with $10 \mu \mathrm{g}$ of Jo2. The liver tissues were fixed with $4 \%$ paraformaldehyde in PBS and were embedded in paraffin. Five-micrometer sections were stained with hematoxylin and eosin.

TUNEL assay. After mice were sacrificed, the liver tissues were immediately fixed with 3.7\% PBS-buffered formaldehyde. In Situ Apoptosis Detection Kits (TA4627, using fluorescein) were obtained from R\&D Systems Inc. (Minneapolis, Minnesota, USA), and TUNEL assay was performed according to the manufacturer's instructions.

Isolation of mouse hepatocytes and sinusoidal endothelial cells. Hepatocytes were isolated by in situ retrograde collagenase perfusion. After perfusion, hepatocytes were dissociated from the digested liver by gently scraping with a glass rod; they were then suspended in DMEM/F12 medium (GIBCO BRL, Grand Island, New York, USA) and filtered through gauze. The cell suspension was then fractionated by Percoll density gradient centrifugation ( $1125 \mathrm{~g}$ for 5 minutes at $4^{\circ} \mathrm{C}$ ). The viability of isolated hepatocytes was assessed by trypan blue dye exclusion. The cells used for all experiments had a viability exceeding $86 \%$. Hepatocytes were counted and resuspended in DMEM/F12 medium containing $10 \% \mathrm{FBS}, 1 \mathrm{nM}$ insulin, $50 \mathrm{nM}$ hydrocortisone, $0.15 \mathrm{mg} / \mathrm{mL}$ methionine, $100 \mathrm{U} / \mathrm{mL}$ penicillin, and $0.1 \mathrm{mg} / \mathrm{mL}$ streptomycin. They were then plated in $60-\mathrm{mm}$ dishes (coated with $0.03 \%$ rat tail collagen) at a density of $1.2 \times 10^{6}$ cells per dish, and incubated in an atmosphere of $95 \%$ air and $5 \% \mathrm{CO}_{2}$. After 3 hours, the medium was removed and replaced with serumfree medium containing $100 \mathrm{U} / \mathrm{mL}$ penicillin and 0.1 $\mathrm{mg} / \mathrm{mL}$ streptomycin, with continued incubation in an atmosphere of $95 \%$ air and $5 \% \mathrm{CO}_{2}$. The sinusoidal endothelial cells (SECs) were isolated and cultured according to the method described by Deleve (29). Briefly, 15 mice were used for each isolation. The livers were mechanically dissociated and then shaken in Gey's buffered saline with $0.05 \%$ type Ia collagenase at $37^{\circ} \mathrm{C}$ for 30 minutes. The suspended hepatic material was pressed through polypropylene mesh and centrifuged. An initial separation was achieved by metrizamide density gradient centrifugation. The thin white layer overlying the metrizamide was then subjected to elutriation. Elutriation was performed in a Beckman J2-21 centrifuge using the JE-6B rotor with standard chambers (Beckman Instruments Inc., Palo Alto, California, USA). The first elutriation was at $875 \mathrm{~g}$ and a pump speed of $27.5 \mathrm{~mL} / \mathrm{min}$; the first $100 \mathrm{~mL}$ of eluate was collected and centrifuged. The pellet was subjected to a second elutriation at $1618 \mathrm{~g}$. The first 100 $\mathrm{mL}$ was collected at a flow rate of $32 \mathrm{~mL} / \mathrm{min}$ and was discarded. Flow rate was increased to $60 \mathrm{~mL} / \mathrm{min}$, and $100 \mathrm{~mL}$ of eluate was collected and centrifuged. The pellet was resuspended in DMEM/F12 low-glucose medium (Irvine Scientific, Santa Ana, California, USA) with $10 \%$ FBS. Cells were plated in 96-well plates coated with rat tail collagen $\left(400,000\right.$ cells $\left./ \mathrm{cm}^{2}\right)$.

DNA fragmentation analysis. One day after mice were pretreated with colchicine in vivo, hepatocytes were isolated and plated for 3 hours as described above. Hepatocytes were then exposed to $100 \mathrm{ng} / \mathrm{mL}$ Jo2 antibody. At the end of each incubation period, the hepatocytes were washed with ice-cold PBS. Hepatocytes were lysed in $500 \mu \mathrm{L}$ lysis buffer $(10 \mathrm{mM}$ Tris- $\mathrm{HCl}$ at $\mathrm{pH}$ 8.0, $10 \mathrm{mM}$ EDTA, $1 \% \mathrm{NP}-40$, and $0.5 \mathrm{mg} / \mathrm{mL}$ proteinase $\mathrm{K}$ ) and were incubated at room temperature for at least 1 hour. The lysates were centrifuged at 20,800 $g$ for 10 minutes at $4^{\circ} \mathrm{C}$. The supernatant was incubated with $50 \mu \mathrm{g} / \mathrm{mL}$ RNase at $37^{\circ} \mathrm{C}$ for 60 minutes. The DNA was extracted with phenol and chloroform (1:1), precipitated by ethanol, and then resuspended in Tris-EDTA buffer. DNA samples (approximately $5 \mu \mathrm{g}$ each) were electrophoretically separated on $2 \%$ agarose gel containing ethidium bromide $(0.5 \mu \mathrm{g} / \mathrm{mL})$. The gel was destained for 20 minutes in water before being viewed and photographed.

Measurement of caspase-3- and caspase-8-like activity. The hepatocytes were pretreated for 12 hours with $1 \mu \mathrm{M}$ colchicine or $1 \mu \mathrm{M} \gamma$-lumicolchicine. After being washed once with culture medium, hepatocytes were exposed to $100 \mathrm{ng} / \mathrm{mL}$ Jo2 antibody or 5,000 U/mL mouse TNF- $\alpha$ (R\&D Systems Inc.) in the presence of $0.5 \mu \mathrm{g} / \mathrm{mL}$ actinomycin D (Sigma Chemical Co.) for 6 hours. The hepatocytes were lysed in $500 \mu \mathrm{L}$ lysis buffer consisting of 10 $\mathrm{mM}$ Tris- $\mathrm{HCl}(\mathrm{pH} 7.5), 10 \mathrm{mM} \mathrm{NaH} \mathrm{PO}_{4} / \mathrm{NaHPO}_{4}$ 

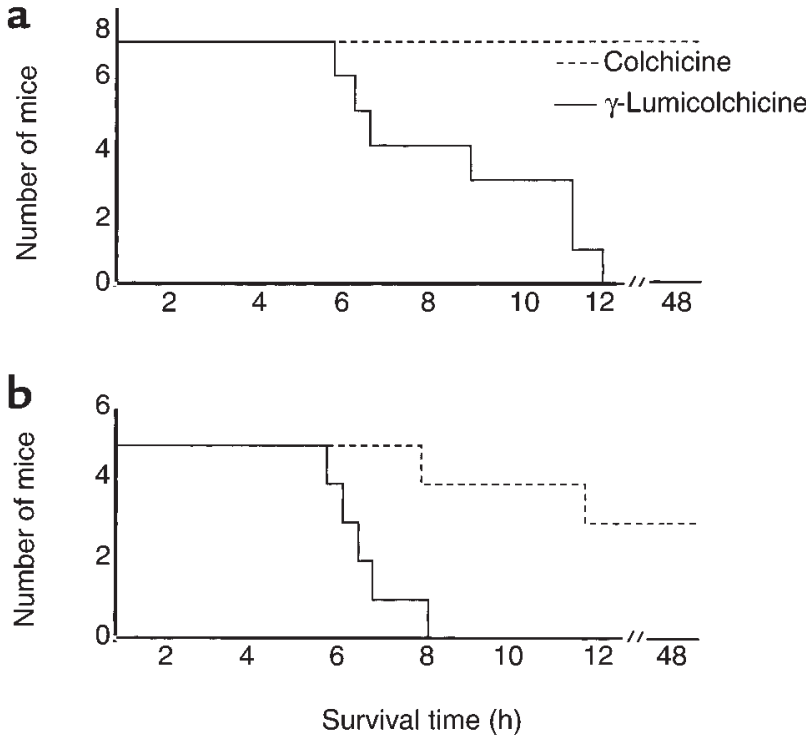

Figure 1

The effect of colchicine on the susceptibility of mice to the lethal effect of Jo2 antibody. (a) Seven mice in each group were injected intraperitoneally with $10 \mu \mathrm{g} J \mathrm{o} 2$ antibody diluted in $200 \mu \mathrm{L}$ PBS 24 hours after treatment with colchicine $(2 \mathrm{mg} / \mathrm{kg}$; dotted line) or $\gamma$ lumicolchicine, an inactive analogue of colchicine (solid line). (b) Five mice in each group were treated as described in a except that the Jo2 dose was increased to $12 \mu \mathrm{g}$.

(pH7.5), $130 \mathrm{mM} \mathrm{NaCl}, 1 \%$ Triton $\mathrm{X}-100$, and $10 \mathrm{mM}$ NaPPi. Caspase-3-like activity in the lysates was measured using caspase-3 assay reagents (PharMingen) according to the manufacturer's instructions, with some modifications. For each sample, $50 \mu \mathrm{L}$ of the cell lysate, $5 \mu \mathrm{L}$ of Ac-DEVD-AMC $(1 \mathrm{mg} / \mathrm{mL}$; a synthetic fluorogenic substrate) and $50 \mu \mathrm{L}$ of reaction buffer $(20 \mathrm{mM}$ HEPES at pH 7.5, 10\% glycerol, and 2 mM DTT) were transferred to a 96-well plate, mixed, and incubated at $37^{\circ} \mathrm{C}$ for 1.5 hours. Caspase- 3 cleaves Ac-DEVD-AMC to release the fluorescent AMC. AMC release in the cell lysates was measured with the CytoFluor 2300 Fluorescence Measurement System (Millipore Corp., Bedford, Massachusetts, USA) using an excitation filter with a wavelength of $360 \mathrm{~nm}$ and an emission filter with a wavelength of $460 \mathrm{~nm}$.

Caspase-8-like activity in the lysates was measured in the same way as was caspase-3, except for the use of AcIETD-AFC as the substrate of FLICE/caspase-8, a different reaction buffer $(20 \mathrm{mM}$ HEPES at $\mathrm{pH} 7.5,100$ $\mathrm{mM} \mathrm{NaCl}, 10 \mathrm{mM}$ DTT, 1 mM EDTA, 0.1\% CHAPS, and $10 \%$ sucrose), and an emission filter with a wavelength of $530 \mathrm{~nm}$.

HOECHST staining. Three hours after plating, hepatocytes were pretreated with $1 \mu \mathrm{M}$ colchicine or $1 \mu \mathrm{M}$ $\gamma$-lumicolchicine and incubated for 12 hours. After being washed once with culture medium, hepatocytes were exposed for 6-12 hours to $100 \mathrm{ng} / \mathrm{mL} J o 2$ antibody or $5,000 \mathrm{U} / \mathrm{mL}$ mouse TNF- $\alpha$ in the presence of $0.5 \mu \mathrm{g} / \mathrm{mL}$ actinomycin $\mathrm{D}$. The cells were then fixed with paraformaldehyde and stained with $2 \mu \mathrm{g} / \mathrm{mL}$ HOECHST 33258 dye for 30 minutes. Cells with bright, fragmented, condensed nuclei were identified as apoptotic cells. In addition, viability and necrosis of hepatocytes was examined by the exclusion of the fluorescent dye SYTOX Green (Molecular Probes Inc., Eugene, Oregon, USA) before fixation. Hepatocytes in 5 random fields (at $\times 300)$ were counted, and SECs in 4 duplicate wells were counted (at $\times 600$ ). The results shown are mean \pm SD of 3 independent experiments.

FACS ${ }^{\circledR}$ for Fas. Immediately after hepatocytes or SECs were isolated, resuspended, and counted as described above, they were washed twice with washing buffer (PBS, $0.1 \% \mathrm{NaN}_{3}$, and $2 \% \mathrm{FBS}$ ) and then incubated with $2 \mu \mathrm{g} / \mathrm{mL}$ R-phycoerythrin-labeled (PE-labeled) anti-Fas Jo 2 antibody (PharMingen) on ice for 20 minutes. After washing 3 times with washing buffer, the density of Fas receptor on the surface of hepatocytes or the SECs was analyzed by FACS ${ }^{\circledR}$.

Immunofluorescence and confocal microscopy. Hepatocytes were allowed to attach to glass coverslips for 3 hours after isolation. After being washed twice with PBS, the cells (on glass coverslips) were fixed with methanol at $-20^{\circ} \mathrm{C}$ for 15 minutes and again washed twice with PBS.
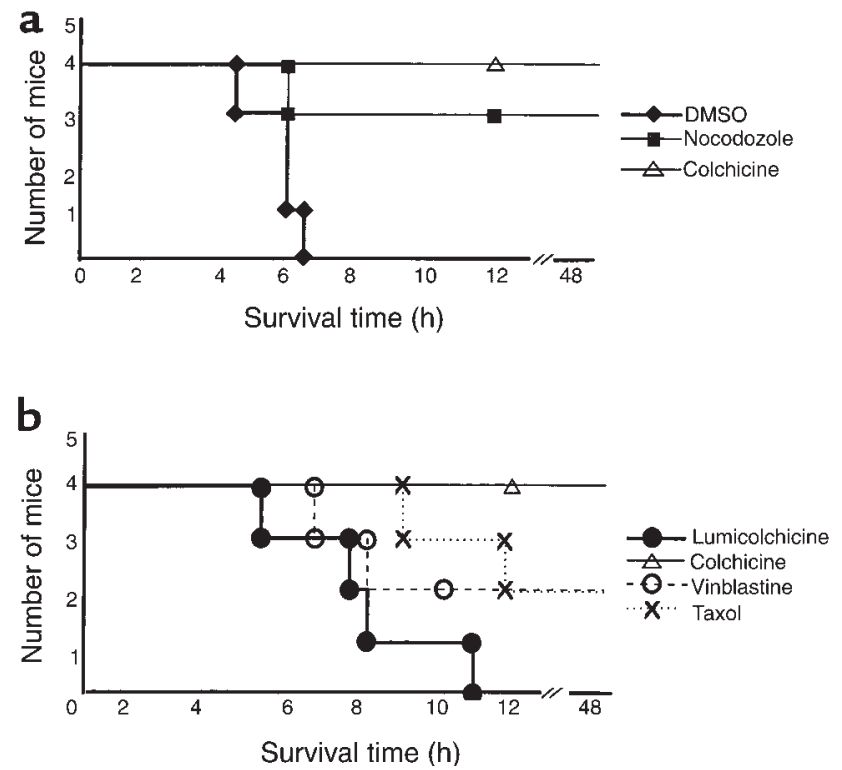

Figure 2

(a) The effect of nocodazole on susceptibility of mice to Jo2 antibody. Four mice in the control group were injected twice with $50 \mu \mathrm{L}$ DMSO at 8 hours and again at 4 hours before intraperitoneal administration of $10 \mu \mathrm{g}$ of Jo2 antibody. Four mice in the nocodazole group were treated in the same way as the control group except that the 50 $\mu \mathrm{L}$ DMSO contained a dose of nocodazole $(10 \mathrm{mg} / \mathrm{kg}$ body weight). Four mice in the colchicine group were injected once with $2 \mathrm{mg} / \mathrm{kg}$ colchicine in $50 \mu \mathrm{L}$ DMSO 8 hours before intraperitoneal administration of $10 \mu \mathrm{g}$ of Jo2 antibody. (b) Comparison of effect of different microtubule inhibitors on susceptibility of mice to Jo2 antibody. Four mice in each group received intraperitoneal injection of $\gamma$-lumicolchicine ( $2 \mathrm{mg} / \mathrm{kg})$, colchicine $(2 \mathrm{mg} / \mathrm{kg})$, vinblastine $(5.0 \mathrm{mg} / \mathrm{kg})$, or Taxol ( $25 \mathrm{mg} / \mathrm{kg}) ; 24$ hours later the mice were injected intraperitoneally with $10 \mu \mathrm{g} \mathrm{Jo} 2$ antibody diluted in $200 \mu \mathrm{L} \mathrm{PBS}$. 

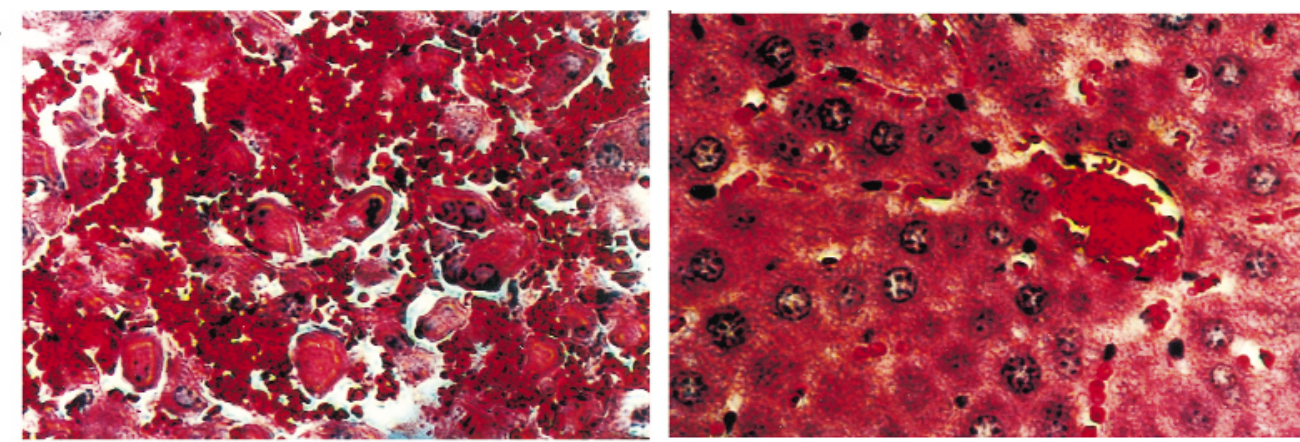

b
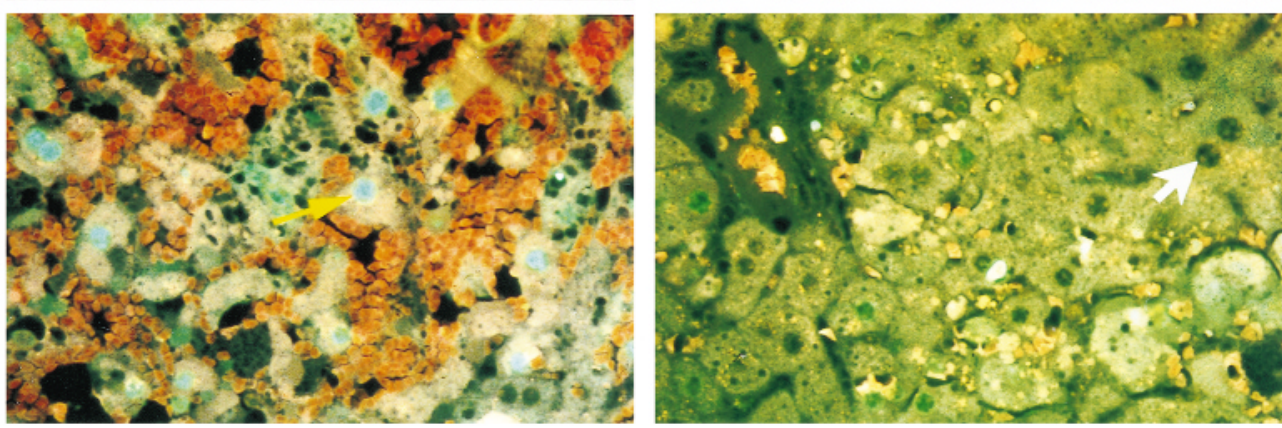

\section{Figure 3}

(a) Representative hepatic histology after Jo2 treatment: comparison of $\gamma$-lumicolchicine and colchicine pretreatment. Hematoxylin and eosin-stained liver sections were prepared 4 hours after injection of $10 \mu \mathrm{g} \mathrm{Jo} 2$ antibody. The liver histology of the $\gamma$-lumicolchicine-pretreated control is shown at left, and the liver histology of the colchicine pretreated mouse is shown at right. $\times 600$. (b) Assessment of Jo2-induced apoptosis of murine liver cells by TUNEL: comparison of $\gamma$-lumicolchicine and colchicine pretreatment. Liver tissues were collected and immediately fixed in $3.7 \%$ PBS-buffered formaldehyde 4 hours after injection of $10 \mu \mathrm{g} \mathrm{Jo} 2$ antibody. Paraffin-embedded tissue sections were stained using a fluorescein TUNEL assay kit according to the manufacturer's instructions. The yellow arrow points to a representative TUNEL-positive (fluorescent) nucleus; the white arrow points to a representative TUNEL-negative nucleus. A liver section from a $\gamma$-lumicolchicine-pretreated mouse is shown at left; a liver section from a colchicine-pretreated mouse is shown at right. $\times 624$.

Nonspecific binding was blocked by incubating in $10 \%$ goat serum in PBS for 10 minutes, and then the cells were incubated with $5 \mu \mathrm{g} / \mathrm{mL}$ PE-labeled Jo2 antibody at $37^{\circ} \mathrm{C}$ for 30 minutes. After washing 3 times with PBS, a drop of anti-fading mounting medium was placed on each sample. Immunofluorescence staining of hepatocytes by PE-Jo2 was analyzed using the Nikon PCM 2000 Personal Confocal Microscope System.

Northern analysis. Total hepatic RNA was extracted from liver tissue with TRIzol reagent (GIBCO BRL) according to the manufacturer's instructions. RNA was denatured at $65^{\circ} \mathrm{C}$ for 5 minutes in loading buffer. It was then electrophoresed through a $1.2 \%$ agarose gel containing $6.8 \%$ formaldehyde and transferred to nitrocellulose membranes (Bio-Rad Laboratories, Hercules, California, USA). The probes for Fas, TNFR-1, and asialoglycoprotein (ASGP) mRNA were a 520-bp fragment of mouse Fas cDNA, a 500-bp fragment of mouse TNFR-1 cDNA, and a 440-bp fragment of mouse ASGP cDNA, which were prepared by RT-PCR and labeled with [ $\left.{ }^{32} \mathrm{P}\right] \mathrm{dCTP}$ using a Megaprimer labeling kit (Amersham Pharmacia Biotech Inc., Piscataway, New Jersey, USA). PCR primer pairs were as follows: Mouse Fas: upstream primer, 5'-CTC AGA AGG ATT ATA TCA AG; downstream primer, 5'-TTT GAG GCA TTC ATT GGT ATG G. Mouse TNFR-1: upstream primer, 5'-TCC GAT CAT CTT ACT TCA TTC AC; downstream primer, 5'-CAG GTA GCG TTG GAA
CTG GTT C. Mouse ASGP: upstream primer, 5 -TAT CAA GAT TTC CAG CAC CTG; downstream primer, 5'-GTC CTT TCA GAG CCA TTG CC. A ${ }^{32}$ P-labeled 0.75-kb fragment of mouse 18S cDNA (American Type Culture Collection, Rockville, Maryland, USA) was used as a control probe for loading. Hybridization was performed in Rapid-Hyb buffer (Amersham Pharmacia Biotec Inc.) under high stringency according to the manufacturer's instructions.

Western analysis. Liver tissue was homogenized with ice-cold lysis buffer (1× PBS, 1\% NP-40, 0.5\% sodium deoxycholate, and $0.1 \%$ SDS containing $100 \mu \mathrm{g} / \mathrm{mL}$ PMSF and $2 \mu \mathrm{g} / \mathrm{mL}$ aprotinin), and incubated on ice for 1 hour. After centrifugation at $120,800 \mathrm{~g}$ for 30 minutes, protein in the supernatants was quantitated using a protein assay from Bio-Rad Laboratories. Forty micrograms of protein per lane was run in 10\% denatured polyacrylamide gel. After transferring protein from the gel to nitrocellulose membranes, the membranes were blocked at $4{ }^{\circ} \mathrm{C}$ overnight in PBS containing $5 \%$ fat-free powdered milk, or at room temperature for 1 hour in PBS plus $0.05 \%$ Tween- 20 (PBS-T) containing $5 \%$ fatfree powdered milk. After briefly rinsing the membranes with PBS-T, they were incubated with $0.4 \mu \mathrm{g} / \mathrm{mL}$ primary antibody for 1 hour at room temperature. Rabbit polyclonal antibody against mouse Fas, rabbit polyclonal antibody against mouse Bcl-XL, rabbit polyclonal antibody against mouse capase- 3 , and mouse mono- 
clonal antibody against human p53 were purchased from Santa Cruz Biotechnology Inc. (Santa Cruz, California, USA). Goat polyclonal antibody against mouse TNFR-1 was obtained from R\&D Systems Inc. After the membranes were washed and incubated with corresponding horseradish peroxidase-labeled secondary antibody (Santa Cruz Biotechnology Inc.) for 45 minutes, proteins were viewed using Luminol ECL reagent (Santa Cruz Biotechnology Inc.).

Isolation of plasma membranes. Plasma membranes from control and colchicine-treated mouse livers were isolated by a modification of the procedure reported by Reinhart et al. (30). Three grams of livers from 3 mice, perfused with saline, was suspended in $30 \mathrm{~mL}$ of a homogenization buffer containing $210 \mathrm{mM}$ mannitol, $60 \mathrm{mM}$ sucrose, $10 \mathrm{mM} \mathrm{KCl}, 10 \mathrm{mM}$ sodium succinate, $1 \mathrm{mM}$ ADP, $0.1 \mathrm{mM}$ EGTA, and $0.25 \mathrm{mM}$ DTT in 10 mM HEPES/KOH buffer ( $\mathrm{pH} 7.5$ ). The suspension was supplemented with protease inhibitors (from a cocktail, as recommended by the supplier), and was homogenized by 8 strokes of a pestle driven at $1,200 \mathrm{rpm}$ at $4-6^{\circ} \mathrm{C}$. Four-milliliter aliquots of this homogenate were layered over a step gradient of $19 \%, 31 \%, 42 \%$, and $52 \%$ Percoll (vol/vol). The tubes were immediately centrifuged at $35,000 \mathrm{~g}$ for 1 minute in a Sorvall RC-25 centrifuge. Plasma membranes separate as a predominant band in the density range of $1.05-1.06 \mathrm{~g} / \mathrm{mL}$; this layer was washed by suspending in $40 \mathrm{~mL}$ of suspension buffer containing $250 \mathrm{mM}$ sucrose and $10 \mathrm{mM}$ HEPES/KOH ( $\mathrm{pH} 7.5$ ), and was centrifuged at $100,000 \mathrm{~g}$ for 45 minutes at $4^{\circ} \mathrm{C}$. The pellets were resuspended in $10 \mathrm{~mL}$ of the suspension buffer by gentle homogenization in a loose-fitting glass Dounce homogenizer. The crude plasma membrane fractions were further purified by centrifugation over a step gradient with $4 \mathrm{~mL}$ each of $12 \%, 33 \%$, and 52\% Percoll (vol/vol) at $35,000 \mathrm{~g}$ for 5 minutes in a Sorvall RC25 centrifuge. Of the 2 bands observed, initial enzyme analyses indicated that the lighter band consisted predominantly of contaminants. Therefore, we collected the denser band (density $1.05-1.06 \mathrm{~g} / \mathrm{mL}$ ) in subsequent studies. The fraction was washed twice by sequential dilution in $40 \mathrm{~mL}$ of suspension buffer containing 250 $\mathrm{mM}$ sucrose, $10 \mathrm{mM}$ HEPES/KOH ( $\mathrm{pH} 7.5$ ), and was centrifuged at $100,000 \mathrm{~g}$ for 45 minutes at $4^{\circ} \mathrm{C}$. The pellet was suspended in a small volume of the suspension buffer supplemented with protease inhibitors (1:25, from a cocktail) and was stored at $-80^{\circ} \mathrm{C}$.

Enzyme assays. Alkaline phosphatase was assayed by quantifying the amount of p-nitrophenol liberated, using p-nitrophenylphosphate as a substrate (31). Succinic dehydrogenase was assayed by the reduction of 2,6-dichlorophenolindophenol by phenazine methosulfate (32). The activities of glucose-6-phosphatase and acid phosphatase were measured by the amount of inorganic phosphate released using glucose-6-phosphate and $\beta$-glycerophosphate, respectively, as substrates (33).

Detection of Fas expression in HepG2 and Hub7 cells. RTPCR combined with Southern analysis was used for determination of Fas expression in hepatoma HepG2 cells and Huh7 cells. Total RNA was extracted from HepG2 cells and Huh7 cells using TRIzol reagent (GIBCO BRL) according to the manufacturer's instructions. Total RNA $(0.5 \mu \mathrm{g})$ was used for cDNA synthesis, followed by PCR amplification using a PerkinElmer RNA-PCR kit (Roche Molecular Systems Inc., Branchburg, New Jersey, USA). Reverse transcription was done at $42^{\circ} \mathrm{C}$ for 30 minutes using random primers. The PCR reaction was performed in a DNA thermal cycler 480 (Perkin-Elmer Citus) for 23 cycles $\left(95^{\circ} \mathrm{C}\right.$ for 30 seconds, $58^{\circ} \mathrm{C}$ for 1 minute, and $72^{\circ} \mathrm{C}$ for 30 seconds). ASGP, used as an internal standard control, was co-reverse transcribed and coamplified with Fas. The PCR products were electrophoresed on a $1.6 \%$ agarose gel followed by Southern analysis with genespecific probes. PCR primer pairs were: Human Fas: upstream, ACT CTA CTG TAT GTG AAC ACT; downstream, TTG GGT ACT TAG CAT GCC ACT G. Human
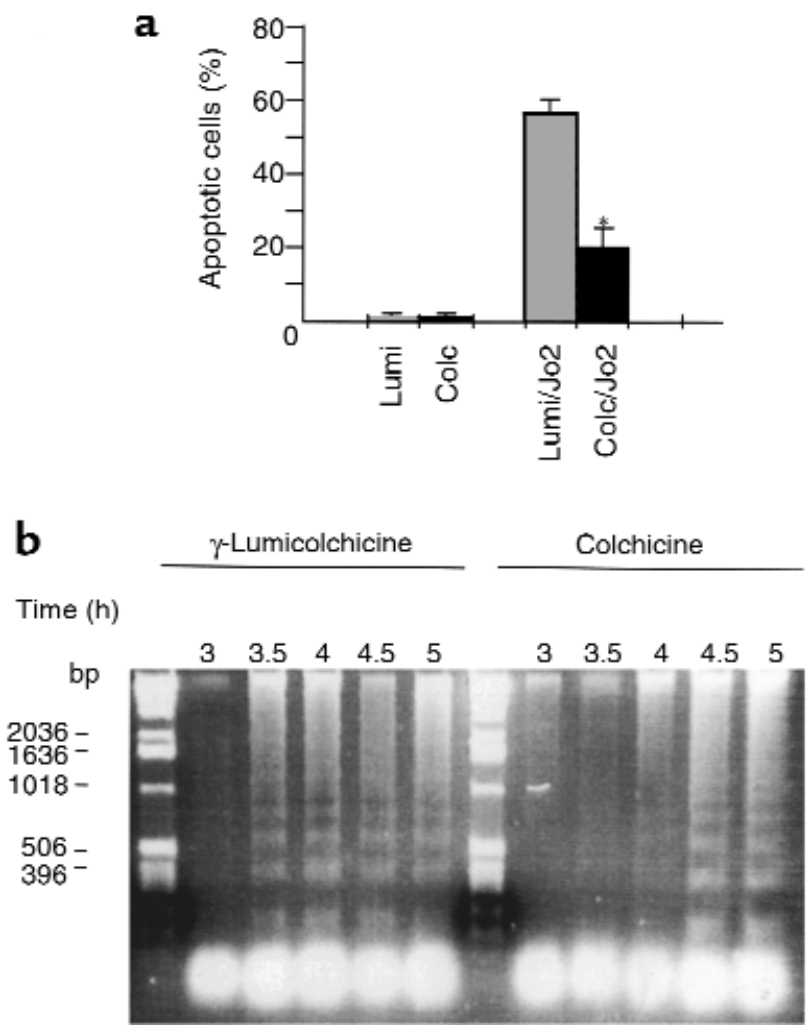

Figure 4

(a) Assessment of Jo2-induced apoptosis of hepatocytes isolated from colchicine-or $\gamma$-lumicolchicine-pretreated mice. Hepatocytes were isolated 24 hours after mice were pretreated with colchicine (Colc) or $\gamma$ lumicolchicine (Lumi). Hepatocytes were allowed to attach to dishes for 3 hours and were then exposed to $100 \mathrm{ng} / \mathrm{mL}$ of Jo 2 antibody for 8 hours. Then the cells were fixed with paraformaldehyde and stained with $2 \mu \mathrm{g} / \mathrm{mL}$ HOECHST 33258 dye for 30 minutes. Five random fields were examined at $\times 300$. Bars at right show the mean \pm SD of 3 independent experiments. ${ }^{*} P<0.05$ vs. $\gamma$-lumicolchicine control by unpaired Student's $t$ test. (b) DNA fragmentation in hepatocytes exposed to Jo2 after colchicine treatment in vivo. The conditions were the same as in a. The time course of DNA laddering is indicated above each lane, with $\gamma$-lumicolchicine pretreatment on the left and colchicine on the right. In the left lane is a 1-kb DNA ladder. 

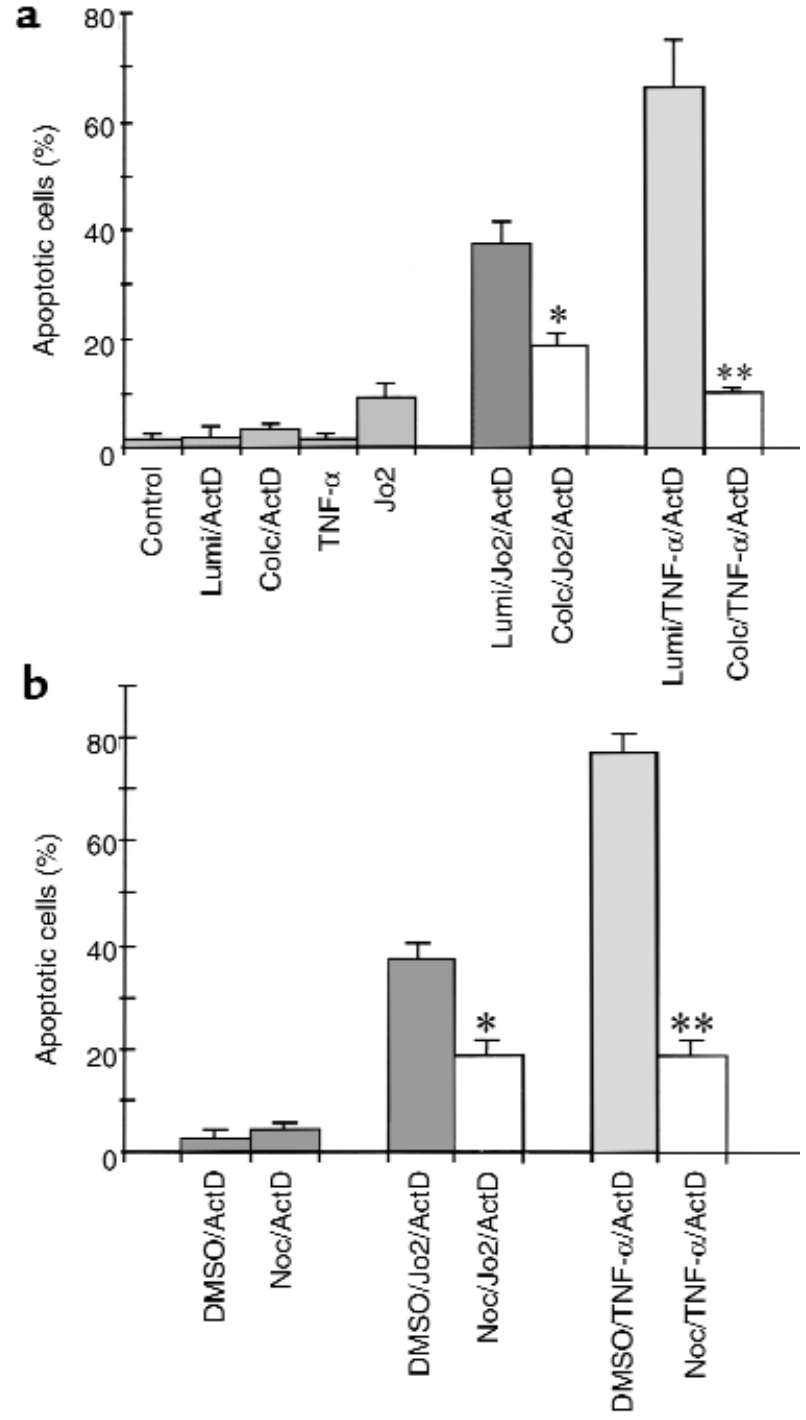

Figure 5

(a) Effect of colchicine on apoptosis induced by Jo2 or TNF- $\alpha$ in actinomycin D-sensitized hepatocytes. Hepatocytes were pretreated with $1 \mu \mathrm{M}$ colchicine or $\gamma$-lumicolchicine for 12 hours and were then exposed to $100 \mathrm{ng} / \mathrm{mL}$ Jo2 antibody or $5,000 \mathrm{U} / \mathrm{mL}$ TNF- $\alpha$ in the presence of $0.5 \mu \mathrm{g} / \mathrm{mL}$ actinomycin D (ActD) for 8 hours. The treatments are indicated below each bar. Apoptosis was assessed as described in Figure 4a. Results are mean \pm SD for 3 independent experiments. ${ }^{*} P<0.05$ and ${ }^{*} P<0.01$ vs. $\gamma$-lumicolchicine control by unpaired Student's $t$ test. (b) Effect of nocodazole on apoptosis induced by Jo 2 or TNF- $\alpha$ in actinomycin D-sensitized hepatocytes. Hepatocytes were pretreated with $20 \mu \mathrm{M}$ nocodazole for 12 hours and then exposed to $100 \mathrm{ng} / \mathrm{mL}$ Jo2 antibody or 5,000 U/mL TNF$\alpha$ in the presence of $0.5 \mu \mathrm{g} / \mathrm{mL}$ actinomycin D for 8 hours. Treatments are indicated below each bar. Apoptosis was assessed as described in Figure 4a. Results are mean \pm SD for 3 independent experiments. ${ }^{*} P<0.05$ and ${ }^{*} P<0.01$ vs. $\gamma$-lumicolchicine control by unpaired Student's $t$ test. Noc, nocodazole.

ASGP: upstream, TCT GCT CCA TGG TCT GCT TC; downstream, GCA CCT CTG TGA CCC TCA CT.

Statistical analysis. Statistical analyses were performed using the Student's $t$ test for unpaired data or ANOVA. $P<0.05$ was considered significant.

\section{Results}

Effect of colchicine on anti-Fas antibody induced lethality. Preliminary experiments in 6- to 7-week-old C57BL/6 mice $(n=6)$ established the $\mathrm{LD}_{50}$ to be $8 \mu \mathrm{g} \mathrm{Jo} 2$ antibody administered intraperitoneally. Colchicine ( $2 \mathrm{mg} / \mathrm{kg})$ alone exhibited no apparent toxic effect or histologic change in liver. To determine whether colchicine decreases the susceptibility of mice to the lethal effect of the anti-Fas antibody Jo2, mice were challenged with intraperitoneal administration of $10 \mu \mathrm{g}$ of Jo2. All the mice treated with colchicine survived the lethal challenge, whereas all the control mice treated with $\gamma$-lumicolchicine succumbed to the challenge and died within 12 hours (Figure 1a). When the dose of Jo2 antibody was increased to $12 \mu \mathrm{g}$, all the mice in the control group died within 8 hours, but only 2 out of 5 colchicine-treated mice died (at more than 8 hours) (Figure $1 \mathrm{~b})$. Thus, protection by colchicine was not complete and could be overcome at a higher dose of Jo2 antibody. The possible protective effect of the other microtubule inhibitors (vinblastine, Taxol, and nocodazole) on the lethal effect of Jo2 antibody was examined. All 3 microtubule inhibitors improved the survival rate of mice challenged with a lethal dose of Jo2 $(10 \mu \mathrm{g})$ (Figure 2). These findings are consistent with protection related to an antimicrotubular effect.

To confirm that the improved survival with colchicine treatment after Jo2 antibody is due to prevention of fulminant liver injury and massive hepatic apoptosis, liver histology was examined and TUNEL staining was performed. Figure 3a shows representative liver histology 4 hours after administration of Jo2 antibody. The $\gamma$ lumicolchicine control mouse liver exhibits extensive fulminant liver injury, whereas only very limited damage is seen in colchicine-pretreated mouse liver. The TUNEL staining (Figure $3 \mathrm{~b}$ ) demonstrated that Jo2 induced massive apoptosis of hepatocytes in the control mouse liver, whereas only spotty apoptosis of hepatocytes was seen around the midzonal area of colchicine-pretreated mouse liver.

Effect of colchicine pretreatment in vivo on susceptibility of cultured hepatocytes to Jo2. To determine whether the protective effect of colchicine is exerted at the hepatocyte level, hepatocytes were isolated from mice pretreated with colchicine or $\gamma$-lumicolchicine for 24 hours. Three hours after plating, hepatocytes were exposed to Jo2 antibody. The sensitivity of hepatocytes to Jo2-induced apoptosis was assessed by both direct counting of apoptotic ratio and DNA laddering. As shown in Figure 4a, the hepatocytes from colchicine-pretreated mice had decreased susceptibility to Jo2-induced apoptosis compared with hepatocytes from $\gamma$-lumicolchicine-pretreated mice. In comparing the time course of DNA laddering between colchicine pretreatment and $\gamma$-lumicolchicine pretreatment after hepatocytes were exposed to $100 \mathrm{ng} / \mathrm{mL}$ Jo2 antibody, colchicine was seen to have delayed Jo2induced apoptosis of hepatocytes (Figure 4b). Thus, after in vivo treatment with colchicine, the sensitivity of cultured hepatocytes from these mice to Jo2 was decreased. 


\section{Figure 6}

(a) FACS $^{\circledR}$ analysis of surface Fas density of hepatocytes. Hepatocytes were isolated 24 hours after mice were pretreated in vivo with colchicine or $\gamma$-lumicolchicine. Hepatocytes were stained with 2 $\mathrm{mg} / \mathrm{mL}$ PE-labeled Jo2 antibody and were assessed for their surface Fas density by FACS ${ }^{\circledR}$ analysis as described in Methods. The solid line represents colchicine-pretreated mice; the dotted line represents $\gamma$ lumicolchicine-pretreated mice. (b) Confocal microscopic analysis of Fas distribution. Hepatocytes were isolated 24 hours after mice were pretreated in vivo with colchicine or $\gamma$-lumicolchicine. Hepatocytes were stained using PE-labeled Jo2 antibody as described in Methods. At left, hepatocytes from $\gamma$-lumicolchicine-pretreated mice show prominent plasma membrane distribution of Fas. At right, hepatocytes from colchicine-pretreated mice show redistribution of Fas to inside the cells, with decreased plasma membrane staining. (c) Effect of colchicine on Fas and TNFR-1 protein of LPM fraction. LPM preparation and Western analysis were performed as described in Methods. For LPM preparation, LPM recovery and enrichment were estimated by marker enzymes; similar results were obtained for colchicine-pretreated samples and $\gamma$-lumicolchicine-pretreated samples. Results for 2 independent experiments are shown. The density of the bands was estimated by Phosphorlmager (Molecular Dynamics, Sunnyvale, California, USA) using the ImageQuant program, revealing that as a result of colchicine pretreatment, both Fas and TNFR-1 doubled in homogenates and decreased by $50 \%$ in LPM.

Direct effect of colchicine treatment on cultured hepatocytes. Next, we addressed the direct action of colchicine by adding it to cultured mouse hepatocytes. The sensitivity of hepatocytes to Jo2 antibody decreased with culture time due to decreased expression of Fas (mRNA) in cultured hepatocytes (data not shown), and possibly also due to other alterations in the dedifferentiating hepatocytes. Compared to the situation represented in Figure $4 \mathrm{a}$, in which Jo2 $(100 \mathrm{ng} / \mathrm{mL})$ exposure for 8 hours induced $56 \pm 3 \%$ apoptosis when added after 3 hours of culture, the apoptosis rate dropped to $11 \pm 5 \%$ when added after 15 hours in culture. Nevertheless, when 0.2 $\mu \mathrm{M}$ colchicine was added 12 hours before Jo 2 exposure, a significant decrease in apoptosis was observed (11 \pm $5 \%$ vs. $3 \pm 1 \% ; P<0.05$ ), with no further decrease up to $1.0 \mu \mathrm{M}$ colchicine. To further demonstrate this, we used actinomycin D to sensitize hepatocytes to Jo2, resulting in enhanced apoptosis. Colchicine pretreatment in culture decreased Jo2-induced apoptosis of the actinomycin D-sensitized hepatocytes (Figure 5a).

To see if this direct effect of colchicine was specific for Fas or was relevant to other death receptors, we assessed the effect of colchicine on TNF- $\alpha$-induced apoptosis in actinomycin D-sensitized hepatocytes. Colchicine exerted a striking protective effect on TNF$\alpha$-induced apoptosis (Figure 5a). Thus, the in vivo protection by colchicine can be attributed to its direct effect on the hepatocytes, and is seen with both Fasand TNFR-1-mediated apoptosis. Nocodazole (20 $\mu \mathrm{M})$, another microtubule inhibitor, also demonstrated protection of cultured hepatocytes from Jo2- or TNF- $\alpha$-induced apoptosis (Figure $5 b$ ), further suggesting that the protection is microtubule-related.

Effect of colchicine on hepatocyte surface Fas receptor. Having demonstrated the protective effects of

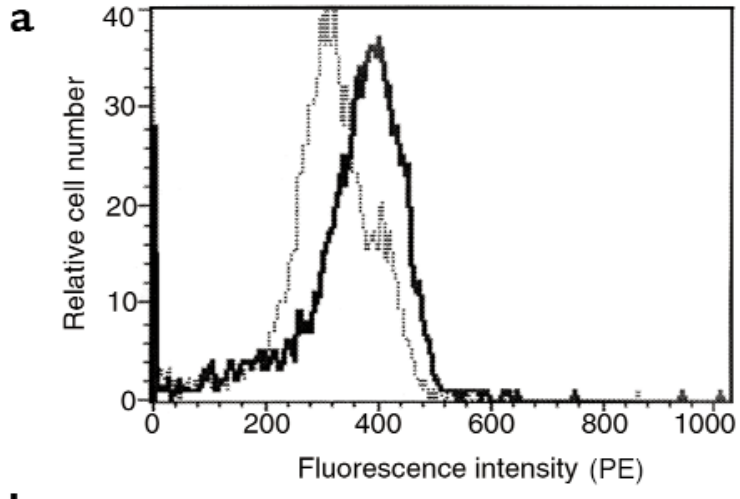

b
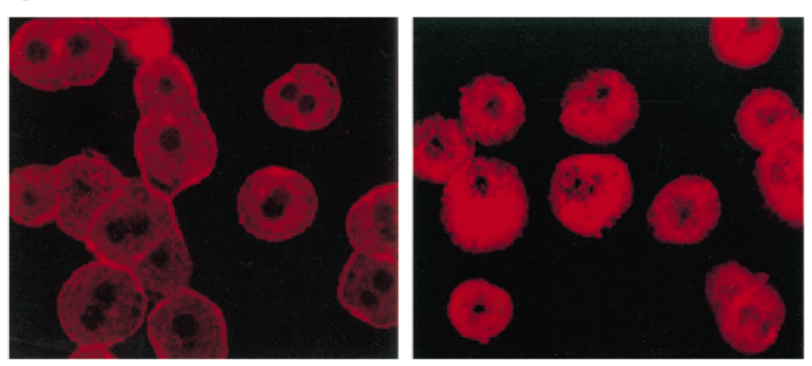

C

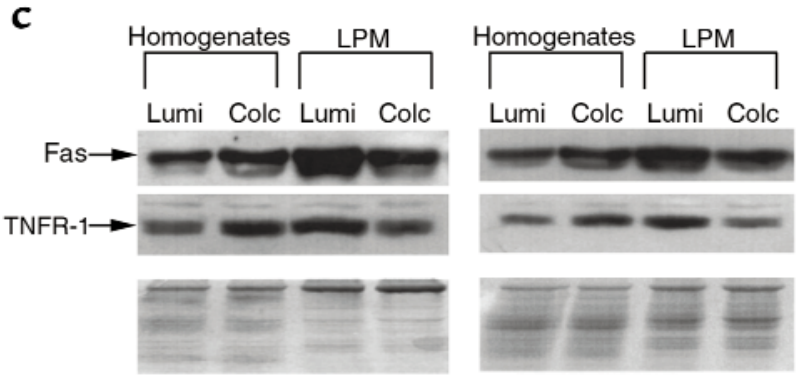

colchicine against Fas-mediated apoptosis in mice in vivo and in cultured hepatocytes, we next addressed the underlying mechanism of the protective effects. Hepatocytes were isolated 1 day after mice were pretreated in vivo with colchicine, and Fas surface expression was determined by FACS ${ }^{\circledR}$ analysis. The results showed that colchicine pretreatment caused a significant decrease $(P<0.05)$ in positively stained hepatocytes $(40 \%, n=3)$ compared with the $\gamma$-lumicolchicine control $(70 \%, n=3)$ (Figure 6a). Thus, colchicine decreased the density of Fas receptors on the hepatocyte surface, suggesting that microtubuledependent targeting of Fas to the surface was inhibited. To further confirm that colchicine pretreatment decreases hepatocyte surface Fas, hepatocytes were stained with PE-labeled Jo2 and examined by confocal microscopy. As shown in Figure 6b, hepatocytes from control mice show distinctive distribution of Fas in plasma membrane compared with hepatocytes from colchicine-pretreated mice. In addition, mouse liver plasma membrane (LPM) fractions were isolated from colchicine- and $\gamma$-lumicolchicine-pretreated mice. Both colchicine- and $\gamma$-lumicolchicine-treated LPM preparations were equally enriched in alkaline phosphate (about 5-fold), and were equivalently and 

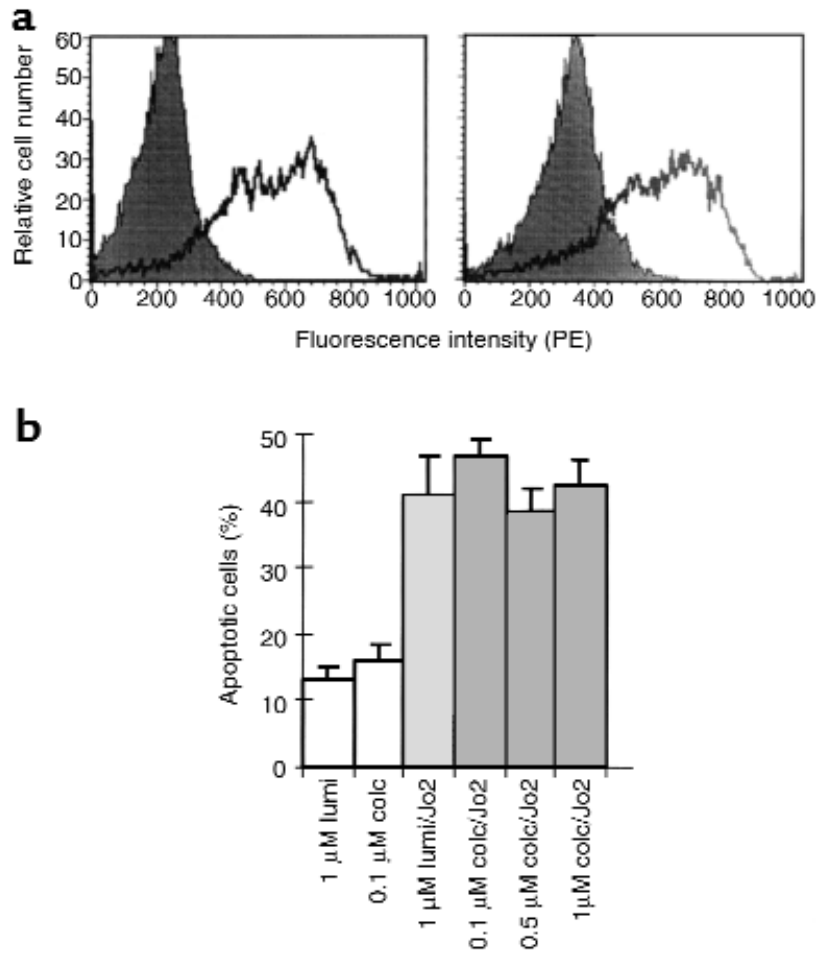

Figure 7

(a) Effect of colchicine on surface Fas density of SECs. SECs were isolated from liver 24 hours after mice were pretreated in vivo with colchicine or $\gamma$-lumicolchicine. The cells were stained with $2 \mathrm{mg} / \mathrm{mL}$ PE-labeled Jo2 antibody and were assessed for surface Fas density by FACS ${ }^{\circledR}$ analysis as described in Methods. Solid peaks are unstained controls; open peaks are stained pretreated cells. Left: SEC from $\gamma$ lumicolchicine-pretreated mice. Right: SEC from colchicine-pretreated mice. (b) Effect of colchicine on Jo2-induced apoptosis of SECs. SECs were pretreated with $1 \mu \mathrm{M}$ colchicine or $\gamma$-lumicolchicine for 12 hours and then were exposed to $100 \mathrm{ng} / \mathrm{mL}$ Jo2 antibody for 8 hours. The treatments are indicated below each bar. Results are the mean \pm SD for 3 independent experiments.

minimally enriched in markers of endoplasmic reticulum, lysosomes, and mitochondria. Western analysis showed that colchicine pretreatment reduced Fas in LPM preparations by about $50 \%$, even though colchicine pretreatment increased Fas content in the whole-liver homogenates (Figure 6c).

Effect of colchicine on Fas density and susceptibility to Jo2 in SECs. Because SECs are known to express Fas and to be potential targets of Jo2, we considered the possibility that some of the protective action of colchicine was directed at these cells. SECs isolated from mouse liver 24 hours after treatment with colchicine or $\gamma$-lumicolchicine were examined for surface Fas expression using FACS ${ }^{\circledR}$ analysis. However, no significant difference was seen between the 2 treatments (Figure 7a). Next, SECs in culture were exposed to Jo2 after 12 hours of pretreatment with colchicine or $\gamma$-lumicolchicine. The SECs exhibited susceptibility to Jo2-induced apoptosis that was not inhibited by colchicine (Figure 7b).

Effect of colchicine pretreatment on Jo2-induced activation of caspase- 8 and caspase- 3 . Caspase- 8 is the initiator cas- pase in the Fas/TNFR-1 death pathway; caspase- 3 is a key executioner caspase for apoptosis. If colchicine acts at the receptor level, we would expect to see decreased activation of initiator and executioner caspases, and no direct inhibition of caspases by colchicine. Therefore, the effect of colchicine pretreatment on Jo2- and TNF$\alpha$-induced activation of caspase- 8 and caspase- 3 was examined. Pretreatment of colchicine reduced both caspase-8- and caspase-3-like activity induced by Jo2 or TNF- $\alpha$ in actinomycin D-sensitized hepatocytes (Figure 8). The effect of colchicine on caspase-8- and caspase-3-like activity did not result from direct inhibition of the 2 proteases by colchicine (data not shown). These data suggest that the effect of colchicine is upstream of caspase-8, consistent with decreased surface death receptors. To further demonstrate that the protective effect of colchicine is related to death receptors, a death receptor-independent apoptotic reagent, staurosporine $(5 \mu \mathrm{M})$, was used to induce the apoptosis of hepatocytes. In contrast to death ligand-induced apoptosis, colchicine had no protective effect on staurosporine-induced apoptosis of hepatocytes after 16 hours (18 $\pm 3 \%$ for $\gamma$-lumicolchicine vs. $19 \pm 2 \%$ for colchicine; not significantly different). We also ruled out other possible protective actions: the effect of colchicine on basal activation and Jo2-stimulated activation of NF- $\kappa \mathrm{B}$ and the effect of colchicine on expression of $\mathrm{Bcl}-2$ and $\mathrm{Bcl}-\mathrm{XL}$ was examined. In vivo treatment with colchicine had no effect on basal activation or Jo2-stimulated activation of NF- $\mathrm{KB}$, or on the expression of Bcl-XL (data not shown). Furthermore, expression of Bcl-2 remained at a negligible level after colchicine pretreatment (data not shown).

The effects of colchicine on expression of Fas and TNFR-1. Because colchicine decreased surface density of Fas, it was important to rule out the possibility that this effect was contributed to by downregulation of Fas transcription or translation. Unexpectedly, Northern analysis showed that 4 hours after colchicine treatment, hepatic expression of Fas had increased up to 3 -fold. To assess the selectivity of this upregulation, we checked another death receptor, TNFR-1, and the hepatic-specific receptor ASGP. As shown in Figure 9, TNFR-1 mRNA was also upregulated in response to colchicine, whereas colchicine had no effect on the abundance of ASGP receptor mRNA. In parallel with the mRNA change, hepatic Fas and TNFR-1 protein were also upregulated by colchicine pretreatment (not shown). Thus, a contribution of downregulation of expression of the death receptors to the protective action of colchicine was ruled out, but unexpectedly, an increase in expression was observed. Because this occurred in the face of decreased surface Fas, these receptors must have accumulated inside the cell. Therefore, a washout experiment was performed to see if the increase in intracellular Fas might eventually reach the surface and increase susceptibility to Jo2 (data not shown). As the effect of colchicine dissipated, the susceptibility to Jo2 (10 $\mu \mathrm{g} /$ mouse) gradually returned to basal susceptibility 


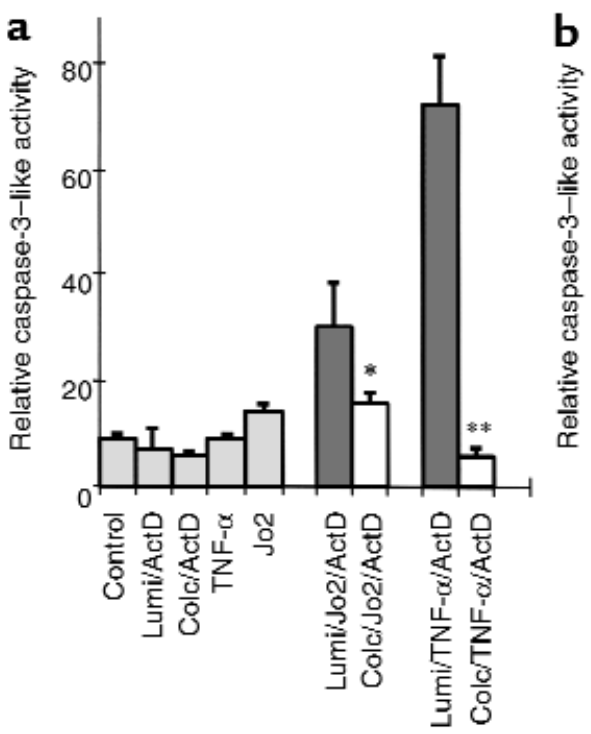

b

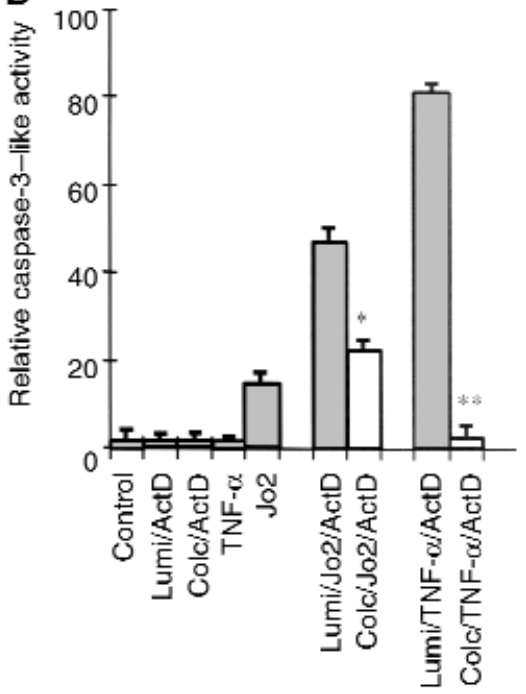

\section{Figure 8}

The effect of colchicine on caspase-8and caspase-3-like activity in cultured hepatocytes. Hepatocytes were pretreated with $1 \mu \mathrm{M}$ colchicine or $\gamma$-lumicolchicine for 12 hours and were then exposed to $100 \mathrm{ng} / \mathrm{mL}$ Jo2 antibody or $5,000 \mathrm{U} / \mathrm{mL}$ TNF- $\alpha$ in the presence of 0.5 $\mu \mathrm{g} / \mathrm{mL}$ actinomycin $\mathrm{D}$ or control treatment for 6 hours, as indicated below each bar. Preparation of cell lysates and measurement of caspase-8- and caspase3-like activity was performed as described in Methods. (a) Caspase-8-like activity. (b) Caspase-3-like activity. Results shown are mean \pm SD of 3 independent experiments. ${ }^{*} P<0.05$ and ${ }^{*} P$ $<0.01$ vs. $\gamma$-lumicolchicine control by unpaired Student's $t$ test. over a period of 4 days after a single dose of colchicine. There was no overshoot in susceptibility to Jo2 during the 4 days after a single injection of colchicine.

The role of $p 53$ in the upregulation of intracellular Fas $m R N A$ and protein by colchicine. To address the mechanism for the upregulation of intracellular Fas mRNA and protein by colchicine, we examined colchicine's effect on p53 expression. The rationale for this was based on 2 things: p53 has been shown to regulate Fas expression (34), and colchicine arrests cell mitosis, which may induce p53 (35). HepG 2 cells with wild-type p53 and Huh7 cells with a mutant defective p53 (34) were treated with colchicine. In HepG2 cells, colchicine treatment led to about a 4fold increase in Fas mRNA, and a parallel increase in p53 protein (not shown). In Huh7 cells, colchicine had no effect on p53 or Fas mRNA (not shown).

In contrast to the hepatoma cells, no change in the expression of p53 was observed in the liver of colchicine-treated mice (data not shown), and Fas mRNA was still upregulated by colchicine in p53knockout mice (not shown). These results suggest that upregulation of Fas expression by colchicine can be either p53 dependent or p53 independent. It is likely that upregulation of Fas expression by colchicine in nondividing cells, such as hepatocytes in intact liver, is p53 independent, whereas in some types of dividing cells it may be p53 dependent.

\section{Discussion}

Despite continued interest in the use of colchicine in the treatment or prevention of liver diseases and its efficacy in some models of liver injury, little is known about its mechanism of action. In view of the expanding insight into the major role of apoptosis in the pathogenesis of liver diseases, we decided to examine the effect of colchicine in liver injury in circumstances involving death receptor signaling. Previous work has suggested that colchicine protects against liver injury induced by TNF in galactosamine-sensitized animals
(27). However, the mechanism was not elucidated. We used agonistic Fas antibody to activate Fas-mediated apoptosis in vivo and in cultured hepatocytes. Pretreatment with colchicine improved survival of mice in vivo by its effect on hepatocytes, which were resistant to apoptosis induced by anti-Fas antibody either after colchicine pretreatment in vivo, or in culture. Inhibition of apoptosis was also reflected in decreased caspase-8- and caspase-3-like activity and in delayed DNA laddering. The effect could not be explained by direct inhibition of caspase-8- and caspase-3-like activity, activation of $\mathrm{NF}-\mathrm{\kappa B}$, or upregulation of $\mathrm{Bcl}-\mathrm{XL}$ or $\mathrm{Bcl}-$ 2 . In contrast, the protection could be attributed to decreased surface density of Fas. Because Fas mRNA and total hepatic Fas protein were not decreased (in fact were increased), the decreased surface expression was not due to downregulation of Fas transcription or translation, and was most consistent with inhibition of microtubule function by colchicine. The similar effect of other antimicrotubule agents further supports this view. Inhibition of microtubule function could impact Fas in 2 related ways: impaired targeting or delivery to the cell surface (which is consistent with our results), and impaired internalization of the receptor-ligand complex. It has been suggested that internalization may contribute to death signaling by a pathway to acidic endosomal vesicles that then activates acidic sphingomyelinase-generating ceramide $(36,37)$, a lipid mediator with effects on mitochondria such as causing cytochrome $c$ release and inhibition of electron transport (38). We did not study this aspect of Fas signaling because the bulk of current evidence suggests that ceramide signaling plays little role in Fas signaling (39), although its role in TNF signaling may be very important. Indeed, the greater inhibitory effect of colchicine on TNF-induced apoptosis than on Jo2-induced apoptosis in sensitized hepatocytes might suggest a dual action of colchicine in decreasing TNFR-1 targeting to the cell surface and receptor-ligand internalization. 


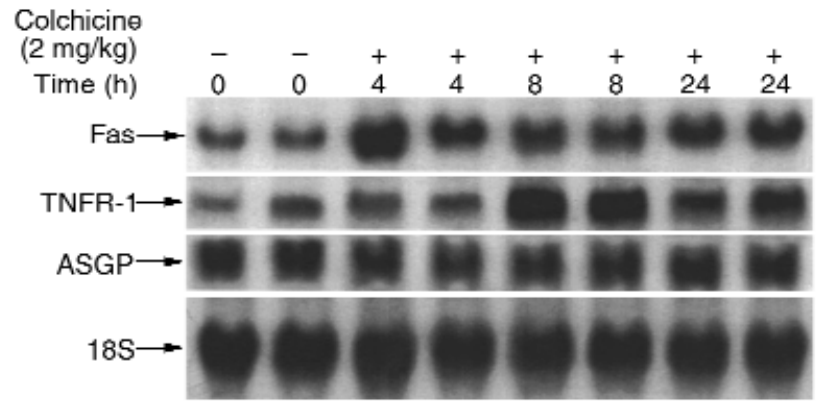

Figure 9

Effect of colchicine on Fas, TNFR-1, and ASGP mRNA in mouse liver. Total RNA was extracted from livers of mice, and $20 \mu \mathrm{g}$ total RNA for each sample was loaded. The time course for colchicine treatment is shown from left to right in pairs of mice as indicated above each lane. Northern blot was probed with ${ }^{32} \mathrm{P}$-labeled mouse Fas cDNA, mouse TNFR-1 cDNA, mouse ASGP cDNA, and mouse 18S cDNA as described in Methods.

Recent evidence has implicated nonparenchymal cells as targets of anti-Fas antibody, suggesting that SEC death contributes to organ damage, particularly in contributing to microvascular collapse and the histologic picture of hemorrhage (40). Although we cannot exclude the possibility that colchicine also protects nonparenchymal cells in vivo, we have not observed a significant decrease in Fas surface density in SECs isolated from colchicine-treated mice, and colchicine did not protect primary cultured SECs that were exposed to Jo2. Therefore, colchicine protects hepatocytes probably its major mechanism of action in vivo. The contribution of nonparenchymal cell apoptosis to overall liver injury remains uncertain.

A few aspects of our studies deserve further comment. Although hepatocytes in vivo are very susceptible to Fas-mediated apoptosis, they rapidly become resistant in culture; this appears to be due at least in part to downregulation of Fas synthesis (data not shown). In addition, hepatocytes are very resistant to TNF-induced apoptosis in vivo and in vitro. However, cotreatment with actinomycin D or cycloheximide markedly increased apoptosis in cultured hepatocytes exposed to either agonistic anti-Fas antibody or TNF$\alpha$. In the case of TNF, it is widely held that sensitization is due to inhibition of transcription or translation of survival genes. In the case of Fas, the mechanism for actinomycin D-induced sensitization is less clear, although it has also been observed by others (41). Despite the sensitization, colchicine protected against apoptosis in both cases. We assume that the protection against TNF involves comparable downregulation of surface density of TNFR-1, although inhibition of internalization of TNF-TNFR1 complex may also contribute. Unfortunately, we could not directly assess this by FACS ${ }^{\circledR}$ analysis due to lack of an appropriate monoclonal antibody to mouse TNFR-1. No other plausible mechanism is apparent, because as noted above, colchicine does not influence
NF- $\kappa \mathrm{B}, \mathrm{Bcl}-2$, or Bcl-XL. Besides, actinomycin D would directly or indirectly eliminate upregulation of these protective factors. In addition, colchicine did not protect hepatocytes from apoptosis induced by staurosporine, which activates apoptosis within the cell, independent of death receptors. Earlier studies in macrophages and endothelial cells demonstrated that antimicrotubular agents decreased surface TNFR binding (42). Although the anti-inflammatory effect of colchicine in gout or periodic fever has been attributed to the effect of inhibition of microtubules on cell proliferation and migration, it is plausible that its anti-inflammatory effect in these conditions may be due to decreased TNFR-1 and Fas on the surface of target cells. Thus, the recent demonstration that increased density of surface TNFR-1 may play a key role in inherited periodic fever demonstrates the potential mechanism for treatment of these conditions with antimicrotubule agents (43).

One surprising finding was the colchicine-induced upregulation of both TNFR-1 and Fas mRNA and protein in vivo. Coupled with downregulation of the surface Fas receptor, upregulation of total Fas equates to accumulation within the cell, although we have not precisely identified the organelle (or organelles) in which it accumulates. After a single dose of colchicine, a wave of Fas movement to the surface did not seem to occur based upon susceptibility to Jo2. Thus, the protective effect of colchicine gradually dissipated with a return to baseline of susceptibility to Jo2. The mechanism for colchicineinduced upregulation of mRNA and protein of death receptors has not been elucidated. Although our data suggest a requirement for p53 in hepatoma cell lines, consistent with the finding of Müller et al. (34), the in vivo effect in mouse liver was clearly independent of p53. We can only speculate that decreased surface density of death receptor somehow signals (or is interpreted by the cell as) a deficiency in Fas and TNFR-1, leading to increased expression of these receptors. The fact that ASGP expression was not altered suggests some specificity for this phenomenon with respect to death receptors.

Our studies demonstrate the potential for use of a readily available class of safe drugs in the form of microtubule inhibitors - such as colchicine - to limit death receptor-mediated injury to the liver. This simple approach may have potential in limiting liver injury in various forms of acute and chronic liver disease, because hepatocellular death mediated by death receptors probably plays an important role in acute and chronic viral hepatitis, autoimmune and alcoholic liver disease, Wilson's disease, and drug-induced liver disease. However, it should be noted that the experimental dose of colchicine in this study is relatively high, and could have toxic effects in patients. Thus, the therapeutic dose and its safety must be evaluated carefully if colchicine or other antimicrotubule agents are to be used to prevent apoptosis in clinical liver disease. 


\section{Acknowledgments}

We thank Aravind Mittur of the Subcellular Organelle Subcore of the University of Southern California Research Center for Liver Diseases (USC RCLD) (grant P01 DK48522) for isolation of LPM membrane. TUNEL staining was performed by the Histology Core, USC-University of California at Los Angeles USCUCLA Alcohol Research Center (P50 AA11999). Confocal microscopy was performed by the Cell Biology Core of the USC RCLD. SEC isolation and culture were performed by the Nonparenchymal Cell Subcore of the USC RCLD. This work was supported by grant AA09526 and project I of USC-UCLA Alcohol Research Center. This work was done in partial fulfillment of the $\mathrm{PhD}$ thesis of Guoping Feng.

1. Vaux, D.L., and Strasser, A. 1996. The molecular biology of apoptosis. Proc. Natl. Acad. Sci. USA. 93:2239-2244.

2. Thompson, C.B. 1995. Apoptosis in the pathogenesis and treatment of disease. Science. 267:1456-1462.

3. Jacobson, M.D., Weil, M., and Raff, M.C. 1997. Programmed cell death in animal development. Cell. 88:347-354.

4. Nagata, S., and Suda, T. 1995. Fas and Fas ligand: lpr and gld mutations. Immunol. Today. 16:39-43.

5. Kerr, J.F.R., Wyllie, A.H., and Currie, A.R. 1972. Apoptosis: a basic biological phenomenon with wide-range implications in tissue kinetics. $\mathrm{Br}$. J. Cancer. 26:239-257.

6. Thornberry, N.A., and Lazebnik, Y. 1998. Caspases: enemies within. Science. 281:1312-1316.

7.Green, D.R. 1998. Apoptotic pathways: the roads to ruin. Cell. 94:695-698.

8. Itoh, N., et al. 1991. The polypeptide encoded by the cDNA for human cell surface antigen Fas can mediate apoptosis. Cell. 66:233-243.

9. Nagata, S., Goldstein, P. 1995. The Fas death factor. Science 267:1449-1456

10. Nagata, S. 1997. Apoptosis by death factor. Cell. 88:355-365.

11. Ashkenazi, A., and Dixit, V.M. 1998. Death receptors: signaling and modulation. Science. 281:1305-1308.

12. Suda, T., Takahashi, T., Golstein, P., and Nagata, S. 1993. Molecular cloning and expression of the Fas ligand: a novel member of the tumor necrosis factor family. Cell. 75:1169-1178.

13. Griffith, T.S., Brunner, T., Fletcher, S.M., Green, D.R., and Ferguson, T.A. 1995. Fas ligand-induced apoptosis as a mechanism of immune privilege. Science. 270:1189-1192.

14. Itoh, N., Suda, T., and Nagata, S. 1993. Lethal effect of the anti-Fas antibody in mice. Nature. 364: 806-809

15. Galle, P.R. 1997. Apoptosis in liver disease. J. Hepatol. 27:405-412.

16. Faubion, W.A., and Gores, G.J. 1999. Death receptors in liver biology and pathobiology. Hepatology. 29:1-4.

17. Mochizuki, K., et al. 1996. Fas antigen expression in liver tissues of patients with chronic hepatitis B. J. Hepatol. 24:1-7.

18. Hiramatsu, N., et al. 1994. Immunohistochemical detection of Fas antigen in liver tissue of patients with chronic hepatitis C. Hepatology. 19:1354-1359.

19. Galle, P.R, et al. 1995. Involvement of the CD95 (APO-1/Fas) receptor and ligand in liver damage. J. Exp. Med. 182:1223-1230.

20. Kondo, T., Suda, T., Fukuyama, H., Adachi, M., and Nagata, S. 1997. Essential roles of the Fas ligand in the development of hepatitis. Nat. Med. 3:409-413.
21. Strand, S., et al. 1998. Hepatic failure and liver cell damage in acute Wilson's disease involve CD95 (APO-1/Fas) mediated apoptosis. Nat. Med. 4:588-593.

22. Adachi, M., et al. 1995. Targeted mutation in the Fas gene causes hyperplasia in the peripheral lymphoid organs and liver. Nat. Genet. 11:294-300

23. Shiraki, K., Tsuji, N., Shioda, T., Isselbacher, K., and Takahashi, H. 1997. Expression of Fas ligand in liver metastasis of human colonic adenocarcinomas. Proc. Natl. Acad. Sci. USA. 94:6420-6425.

24. Joshi, H.C. 1998. Microtubule dynamics in living cells. Curr. Opin. Cell Biol. 10:35-44.

25. Muriel, P., Quintanar, M.E., and Perezalvarez, V. 1993. Effect of colchicine on acetaminophen-induced liver damage. Liver. 13:217-221.

26. Favari, L., Perezalvarez, V. 1997. Comparative effects of colchicine and silymarin on CCL4 chronic liver damage in rats. Arch. Med. Res. 28:11-17.

27. Tiegs, G., Freudenberg, M.A., Galanos, C., and Wendel, A. 1992. Colchicine prevents tumor necrosis factor-induced toxicity in vivo. Infect. Immun. 60:1941-1945.

28. Kershenobich, D., et al. 1988. Colchicine in the treatment of cirrhosis of the liver. N. Engl. J. Med. 318:1709-1713.

29. Deleve, L.D. 1994. Dacarbazine toxicity in murine liver cells: a model of hepatic endothethial injury and glutathione defense. J. Pharmacol. Exp. Ther. 268:1261-1270.

30. Reinhart, P.H., Taylor, W.M., and Bygrave, F.L. 1982. A procedure for the rapid preparation of mitochondria from rat liver. Biochem. J. 204:731-735.

31. Scharschmidt, B.F., Keeffe, E.B., Blankenship, N.M., and Ockner, R.K. 1979. Studies of relationships among bile flow, liver plasma membrane $\mathrm{Na} / \mathrm{K}$ ATPase, and membrane microviscosity in the rat. J. Clin. Invest. 64:1590-1598.

32. Hatefi, Y., and Stigall, D.L. 1978. Preparation and properties of succinate: ubiquinone xoreductase (complex II). Methods Enzymol. 53:21-27.

33. Fernandez-Checa, J.C., Takikawa, H., Horie, T., Ookhtens, M., and Kaplowitz, N. 1992. Canalicular transport of reduced glutathione in normal and mutant Eisai hyperbilirubinemic rats. J. Biol. Chem. 267:1667-1673.

34. Müller, M., et al. 1997. Drug-induced apoptosis in hepatoma cells is mediated by the CD95 (APO-1/Fas) receptor/ligand system and involves activation of wild-type p53. J. Clin. Invest. 99:403-413.

35. Sorger, P.K., Dobles, M., Tournebize, R., and Hyman, A.A. 1997. Coupling cell division and cell death to microtubule dynamics. Curr. Opin. Cell Biol. 9:807-814.

36. Hofmann, K., and Dixit, V.M. 1998. Ceramide in apoptosis: does it really matter? Trends Biochem. Sci. 23:374-377.

37. Pastorino, J.G., et al. 1996. The cytotoxicity of tumor necrosis factor depends on induction of the mitochondrial permeability transition. J. Biol. Chem. 271:29792-29798.

38. Garcia-Ruiz, C., Colell, A., Mari, M., Morales, A., and Fernandez-Checa, J.C. 1997. Direct effect of ceramide on the mitochondrial electron transport chain leads to generation of reactive oxygen species. Role of mitochondrial glutathione. J. Biol. Chem. 272:11369-11377.

39. Cock, J.G., Tepper, A.D., de Vries, E., van Blitterswijk, W.J., and Borst, J. 1998. CD95 (Fas/APO-1) induces ceramide formation and apoptosis in the absence of a functional acid sphingomyelinase. J. Biol. Chem. 273:7560-7565.

40. Wanner, G.A., Mica, L., Wanner-Schmid, E., Kolb, S.A., Hentze, H., et al. 1999. Inhibition of caspase activity prevents CD95-mediated hepatic microvascular perfusion failure and restores Kuffer cell clearance capacity. FASEB J. 13:1239-1248.

41. Ni, R., et al. 1994. Fas-mediated apoptosis in primary cultured mouse hepatocytes. Exp. Cell Res. 215:332-337.

42. Ding, A.H., Porteu, F., Sanchez, E., and Nathan, C.F. 1990. Downregulation of tumor necrosis factor receptors on macrophages and endothelial cells by microtubule depolymerizing agents. J. Exp. Med. 171:715-727.

43. McDermott, M.F., et al. 1999. Germline mutations in the extracellular domains of the $55 \mathrm{kDa}$ TNF receptor, TNFR1, define a family of dominantly inherited autoinflammatory syndromes. Cell. 97:133-144. 